\title{
Rare Earth Doped Lanthanum Calcium Borate Polycrystalline Red Phosphors
}

\author{
H. H. Xiong, ${ }^{1}$ C. Zhu, ${ }^{1}$ X. Zhao, ${ }^{2}$ Z. Q. Wang, ${ }^{1}$ and H. Lin ${ }^{1}$ \\ ${ }^{1}$ School of Textile and Material Engineering, Dalian Polytechnic University, Dalian 116034, China \\ ${ }^{2}$ School of Information Science and Engineering, Dalian Polytechnic University, Dalian 116034, China \\ Correspondence should be addressed to H. Lin; wjs@dlpu.edu.cn
}

Received 19 March 2014; Accepted 15 July 2014; Published 5 August 2014

Academic Editor: Somchai Thongtem

Copyright (c) $2014 \mathrm{H}$. H. Xiong et al. This is an open access article distributed under the Creative Commons Attribution License, which permits unrestricted use, distribution, and reproduction in any medium, provided the original work is properly cited.

\begin{abstract}
Single-phased $\mathrm{Sm}^{3+}$ doped lanthanum calcium borate $\left(\mathrm{Sm}_{x} \mathrm{La}_{2-x} \mathrm{CaB}_{10} \mathrm{O}_{19}\right.$, $\left.\mathrm{SLCB}, x=0.06\right)$ polycrystalline red phosphor was prepared by solid-state reaction method. The phosphor has two main excitation peaks located at $398.5 \mathrm{~nm}$ and $469.0 \mathrm{~nm}$, which are nicely in accordance with the emitting wavelengths of commercial near-UV and blue light emitting diode chips. Under the excitation of $398.0 \mathrm{~nm}$, the dominant red emission of $\mathrm{Sm}^{3+}$ in SLCB phosphor is centered at $598.0 \mathrm{~nm}$ corresponding to the transition of ${ }^{4} \mathrm{G}_{5 / 2} \rightarrow{ }^{6} \mathrm{H}_{7 / 2}$. The $\mathrm{Eu}^{3+}$ fluorescence in the red spectral region is applied as a spectroscopic probe to reveal the local site symmetry in the host lattice and, hence, Judd-Ofelt parameters $\Omega_{t}(t=2,4)$ of $\mathrm{Eu}^{3+}$ in the phosphor matrix are derived to be $3.62 \times 10^{-20}$ and $1.97 \times 10^{-20} \mathrm{~cm}^{2}$, indicating a high asymmetrical and strong covalent environment around rare earth luminescence centers. Herein, the red phosphors are promising good candidates employed in white light emitting diodes (LEDs) illumination.
\end{abstract}

\section{Introduction}

White light emitting diodes (LEDs) are considered as the next generation solid-state lighting systems because of their excellent properties such as high efficiency, low power consumption, long lifetime, and lower toxicity [1-6]. The LED based solid-state lighting techniques have gained great achievements since the white LEDs became commercially available by Nichia Chemical Co. in 1997 [7-9]. There are three ways to produce white LEDs: (i) combining a blue LED with a yellow phosphor, for example, $\mathrm{Y}_{3} \mathrm{Al}_{5} \mathrm{O}_{12}: \mathrm{Ce}^{3+}$, (ii) mixing red, green, and blue emissions from three LEDs, and (iii) exciting red/green/blue tricolor phosphors with a near-UV LED $(370-410 \mathrm{~nm})$. The third is a flexible and convenient way to obtain high quality white LEDs due to the following advantages, generated white color by phosphors, that is, high tolerance to UV chips' color variation and excellent color rendering index [10]. The main tricolor phosphors for near-UV InGaN-based LEDs are still under developing just as $\mathrm{BaMgAl}_{10} \mathrm{O}_{17}: \mathrm{Eu}^{2+}$ for blue, $\mathrm{ZnS}: \mathrm{Cu}^{+} / \mathrm{Al}^{3+}$ for green, and $\mathrm{Y}_{2} \mathrm{O}_{2} \mathrm{~S}: \mathrm{Eu}^{3+}$ for red [11-13]. Among them, the red phosphor has received much attention due to the fact that it can improve color rendering index; therefore it is meaningful to develop numerous red phosphors with higher efficiency to improve the performance of white LEDs [13-17].

During the past decades, rare earth ions doped in various host materials have been widely studied due to their characteristic luminescence properties. Among the rare earth ions, $\mathrm{Sm}^{3+}, \mathrm{Eu}^{3+}, \mathrm{Tb}^{3+}$, and $\mathrm{Dy}^{3+}$ are important activator ions for producing visible light [18-25]. $\mathrm{Sm}^{3+}$ activated luminescent materials have received much attention at present $[26,27]$. They show bright emissions in orange and red regions attributed to the transitions from the excited state ${ }^{4} \mathrm{G}_{5 / 2}$ to the ground state ${ }^{6} \mathrm{H}_{5 / 2}$ and the other state ${ }^{6} \mathrm{H}_{J}(J=$ $7 / 2,9 / 2$, and $11 / 2$ ), which can be used in high density optical storage, temperature sensors, under sea communication, various fluorescent devices, color display, and visible solidstate lasers [2, 28-30]. Luminescence of $\mathrm{Eu}^{3+}$ is especially useful to probe the local structure of luminescent centers in a host lattice because of its simple energy level structure, great sensitivity to ligand field, and similar lanthanide chemical properties to the other rare earth ions [31-33]. 
Growing interest recently has been focused on luminescence of trivalent rare earth ions in phosphates, tungstates, borates, molybdates, and aluminates, among which rare earth doped borates are especially attractive because of their wide UV transparency, exceptional optical damage thresholds, excellent chemical and thermal stability, and high luminescence efficiency [34-42]. Hence, a borate phosphor which efficiently emits red fluorescence under the UV and blue light excitation is of great significance to be synthesized for practical applications. The compound $\mathrm{La}_{2} \mathrm{CaB}_{10} \mathrm{O}_{19}(\mathrm{LCB})$ is chemically stable and nonhygroscopic, which belongs to the monoclinic system with the space group of C2 and the lattice parameters $a=1.1043 \mathrm{~nm}, b=0.6563 \mathrm{~nm}, c=0.9129 \mathrm{~nm}$, $\alpha=\gamma=90^{\circ}$, and $\beta=91.47^{\circ}[43,44]$. The effect of $\mathrm{Sm}^{3+}$ doping in LCB host is seductive to be developed as a red phosphor for solid-state LED lighting.

Herein, $\mathrm{Sm}^{3+}$ activated lanthanum calcium borate phosphor $\left(\mathrm{Sm}_{x} \mathrm{La}_{2-x} \mathrm{CaB}_{10} \mathrm{O}_{19}\right.$, SLCB) was prepared by the solidstate reaction technique, and an attempt was made to investigate its luminescence characteristics. $\mathrm{Eu}^{3+}$ was adopted as a probe in ELCB $\left(\mathrm{Eu}_{x} \mathrm{La}_{2-x} \mathrm{CaB}_{10} \mathrm{O}_{19}, \mathrm{ELCB}\right)$ phosphor through the calculation of $J-O$ parameters to reflect the local microenvironment around the rare earth ions in the compounds. The bright red fluorescence obtained from SLCB phosphor suggests that the as-prepared phosphor is a promising red luminescent material for white LEDs.

\section{Experiments}

SLCB phosphor was synthesized by a solid-state reaction route at high temperature using the following chemical reaction:

$$
\begin{aligned}
x \mathrm{Sm}_{2} \mathrm{O}_{3} & +(2-x) \mathrm{La}_{2} \mathrm{O}_{3}+2 \mathrm{CaCO}_{3}+20 \mathrm{H}_{3} \mathrm{BO}_{3} \\
\longrightarrow & 2 \mathrm{Sm}_{x} \mathrm{La}_{2-x} \mathrm{CaB}_{10} \mathrm{O}_{19}+2 \mathrm{CO}_{2} \uparrow+30 \mathrm{H}_{2} \mathrm{O} \uparrow .
\end{aligned}
$$

Here, the $x$ value of SLCB sample is the molar replacement of $\mathrm{La}^{3+}$ by $\mathrm{Sm}^{3+}$, which is adopted to be 0.06 to maintain the brightness of phosphors and avoid the fluorescence quenching because of high concentration doping. Reagents $\mathrm{La}_{2} \mathrm{O}_{3}$ (99.99\%), $\mathrm{CaCO}_{3}$ (99.99\%), $\mathrm{H}_{3} \mathrm{BO}_{3}(99.9 \%)$, and $\mathrm{Sm}_{2} \mathrm{O}_{3}$ (99.99\%) were used as raw materials. They were weighed according to the stoichiometric proportion, except for $\mathrm{H}_{3} \mathrm{BO}_{3}$ with an excess of $6.5 \mathrm{wt} \%$ to compensate for the volatilization of $\mathrm{B}_{2} \mathrm{O}_{3}$ at high temperature. After being ground and mixed thoroughly in an agate mortar, the mixture was placed into an electric furnace and preheated at $500^{\circ} \mathrm{C}$ for $10 \mathrm{~h}$. Being cooled and ground again, the mixture was sintered at $930^{\circ} \mathrm{C}$ for $24 \mathrm{~h}$ twice with the intermediate grinding.

The crystallographic structure of SLCB powders was characterized by $\mathrm{X}$-ray powder diffraction analysis using a D/Max-3B X-ray diffractometer with $40 \mathrm{kV}, 20 \mathrm{~mA}$. The excitation and emission spectra were recorded on a Jobin Yvon FluoroLog-3 spectrophotometer with a R928 photomultiplier tube (PMT) detector, and a commercial CW Xelamp was used as pump source. A JSM-6460LV scanning electron microscopy was used for the observation of particle morphology. The photographs of the samples were taken by a Sony $\alpha 200$ digital camera. ELCB phosphor was prepared by the same way except that $\mathrm{Eu}_{2} \mathrm{O}_{3}$ was used instead of $\mathrm{Sm}_{2} \mathrm{O}_{3}$ and the measurements were carried out at the same condition as SLCB phosphor.

\section{Results and Discussion}

3.1. X-Ray Diffraction Analysis. To check the phase purity and the structure of the sample, the powder X-ray diffraction (XRD) measurement for the sample was carried out. Figure 1 presents a comparison between the experimental result for SLCB phosphor and JCPDS card 54-0033 $\left(\mathrm{La}_{2} \mathrm{CaB}_{10} \mathrm{O}_{19}\right)$. The observed peaks are in good agreement with the JCPDS data indicating that the main phase of the prepared phosphor is LCB. Because of lanthanide contraction, rare earth ions have similar radius, coordination environment, and physicalchemical properties. When $\mathrm{La}^{3+}$ in the lattice is replaced by $\mathrm{Sm}^{3+}$, the crystal structure does not change dramatically. The doped product crystallizes as monoclinic structure with a space group of $\mathrm{C} 2$ and lattice parameters values $a=$ $1.1028 \mathrm{~nm}, b=0.6556 \mathrm{~nm}, c=0.9114 \mathrm{~nm}$, and $\beta=91.431^{\circ}$, which is almost consistent with pure LCB phase [44, 45]. These results show that the $\mathrm{Sm}^{3+}$ has been incorporated into LCB lattices successfully and the small amount of $\mathrm{Sm}^{3+}$ ions has negligible effect on the basic crystal structure of LCB. The same result was verified in ELCB phosphor.

\subsection{Photoluminescence Characteristics of SLCB Phosphor.} The excitation spectrum of SLCB phosphor monitored at $598.0 \mathrm{~nm}$ consists of several bands peaking at 245.0, 340.0, $358.0,370.0,398.5,412.5$, and $469.0 \mathrm{~nm}$ as depicted in Figure 2. The broadband around $245.0 \mathrm{~nm}$ is due to the charge transfer (CT) band of $\mathrm{Sm}^{3+}-\mathrm{O}^{2-}[45,46]$. The other excitation peaks at 340.0, 358.0, 370.0, 398.5, 412.5, and $469.0 \mathrm{~nm}$ have been assigned to the $4 \mathrm{f}-4 \mathrm{f}$ inner shell transitions of $\mathrm{Sm}^{3+}$ [4749]. The efficient excited wavelength range of $\mathrm{Sm}^{3+}$ in SLCB phosphor covers the whole long-wavelength UV, purple, blue, and bluish-green spectral regions. This suggests that the effective excitation range matches the output wavelengths of InGaN-based LED chips well; thus the phosphors have potential application in the solid-state LED lighting.

Figure 3 is the emission spectrum of SLCB phosphor excited by $398.0 \mathrm{~nm}$. The characteristic emissions of SLCB phosphor consist of five emission bands, which are attributed to the transitions from ${ }^{4} \mathrm{G}_{5 / 2}$ state to ${ }^{6} \mathrm{H}_{J}(J=$ $5 / 2,7 / 2,9 / 2,11 / 2$, and $13 / 2$ ) states of $\mathrm{Sm}^{3+}$. Among these, the strongest emission peak located at $598.0 \mathrm{~nm}$ originates from the typical transition ${ }^{4} \mathrm{G}_{5 / 2} \rightarrow{ }^{6} \mathrm{H}_{7 / 2}$ and the other peaks at 562.0, 646.5, 706.0, and $735.0 \mathrm{~nm}$ are attributed to the transitions of ${ }^{4} \mathrm{G}_{5 / 2} \rightarrow{ }^{6} \mathrm{H}_{5 / 2},{ }^{4} \mathrm{G}_{5 / 2} \rightarrow{ }^{6} \mathrm{H}_{9 / 2}$, ${ }^{4} \mathrm{G}_{5 / 2} \rightarrow{ }^{6} \mathrm{H}_{11 / 2}$, and ${ }^{4} \mathrm{G}_{5 / 2} \rightarrow{ }^{6} \mathrm{H}_{13 / 2}$, respectively [5054]. Among these emission peaks, the transition emission ${ }^{4} \mathrm{G}_{5 / 2} \rightarrow{ }^{6} \mathrm{H}_{7 / 2}(598.0 \mathrm{~nm}$, orangish red) with $\Delta J= \pm 1$ is a magnetic dipole (MD) allowed one, but it is also electric dipole (ED) dominated one and the other transition ${ }^{4} \mathrm{G}_{5 / 2} \rightarrow$ ${ }^{6} \mathrm{H}_{9 / 2}(646.5 \mathrm{~nm}$, red) is purely an $\mathrm{ED}$ one. The MD transition does not appreciably depend on the chemical surroundings of the luminescent center and its symmetry; however, the ED 


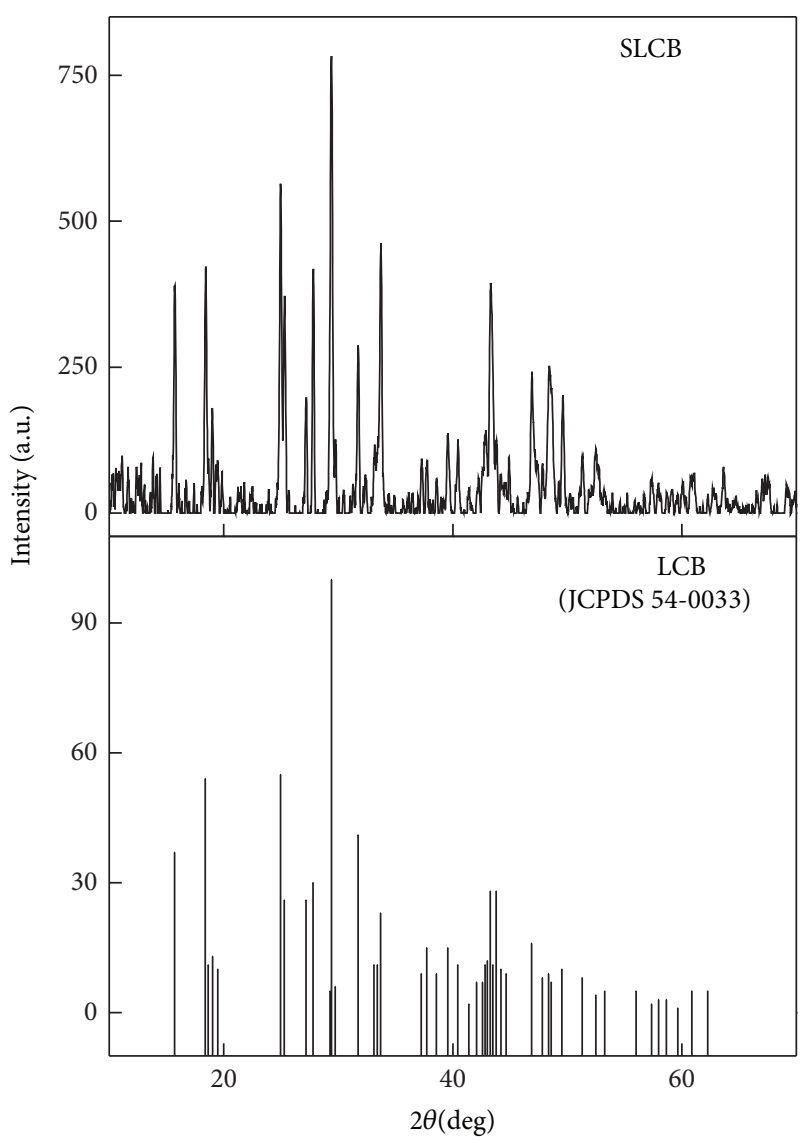

Figure 1: X-ray diffraction patterns of SLCB phosphor and the referenced LCB (JCPDS number 54-0033).

transition belongs to hypersensitive transitions. Generally, the intensity ratio of $\mathrm{ED}$ to MD transitions has been used to evaluate the symmetry of the local environment of the trivalent $4 \mathrm{f}$ ions. The greater the intensity of the ED transition, the more the asymmetry nature [55]. In this work, the emission due to ${ }^{4} \mathrm{G}_{5 / 2} \rightarrow{ }^{6} \mathrm{H}_{9 / 2}$ (ED) transition of $\mathrm{Sm}^{3+}$ is more intense than ${ }^{4} \mathrm{G}_{5 / 2} \rightarrow{ }^{6} \mathrm{H}_{5 / 2}$, specifying the asymmetric nature of host matrix. And the three main emission peaks of SLCB phosphor always split just similarly to the reports of $\mathrm{LiBaBO}_{3}: \mathrm{Sm}^{3+}$ [56], $\mathrm{Gd}_{2} \mathrm{MoO}_{6}: \mathrm{Sm}^{3+}$ [57], and $\mathrm{GdVO}_{4}: \mathrm{Sm}^{3+}$ [58]. Those splits result from the crystal field effects, and the spilt extents are related to the structure characteristic of the crystal field.

3.3. Intensity Parameters of the Spectroscopic Probe $\mathrm{Eu}^{3+}$ in ELCB Phosphor. Figure 4 presents the emission spectrum of ELCB phosphor excited at $391.0 \mathrm{~nm}$ in the wavelength of 560$720 \mathrm{~nm}$. There are several typical emission bands around 560$720 \mathrm{~nm}$ assigned to the ${ }^{5} \mathrm{D}_{0} \rightarrow{ }^{7} \mathrm{~F}_{J}(J=0-4)$ transitions of $\mathrm{Eu}^{3+}$ [59-63], of which the red emission band at $617 \mathrm{~nm}$ is the most intense one due to the electric dipole transition ${ }^{5} \mathrm{D}_{0} \rightarrow{ }^{7} \mathrm{~F}_{2}$.

Luminescence of $\mathrm{Eu}^{3+}$ is especially useful to probe the local symmetry and bonding characteristics of luminescent

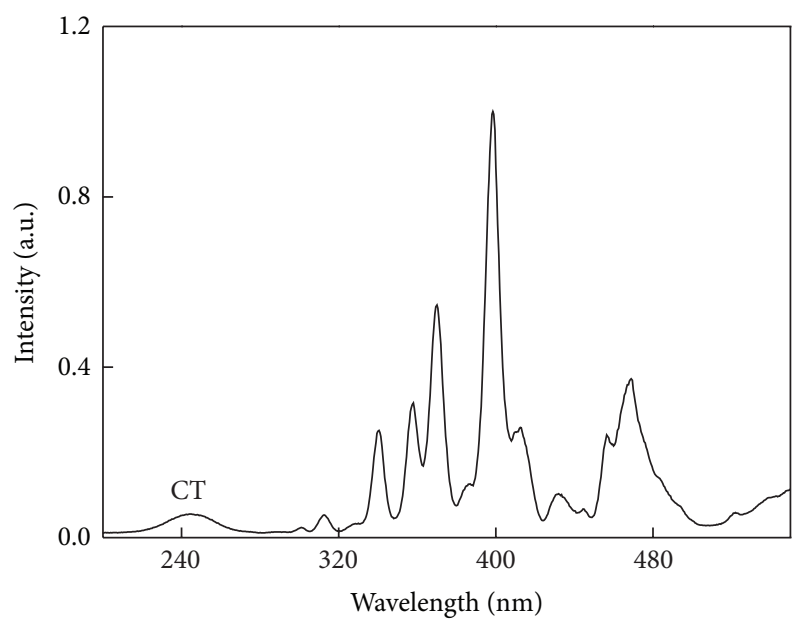

FIGURE 2: Excitation spectrum of SLCB phosphor $\left(\lambda_{\mathrm{em}}=598.0 \mathrm{~nm}\right)$.

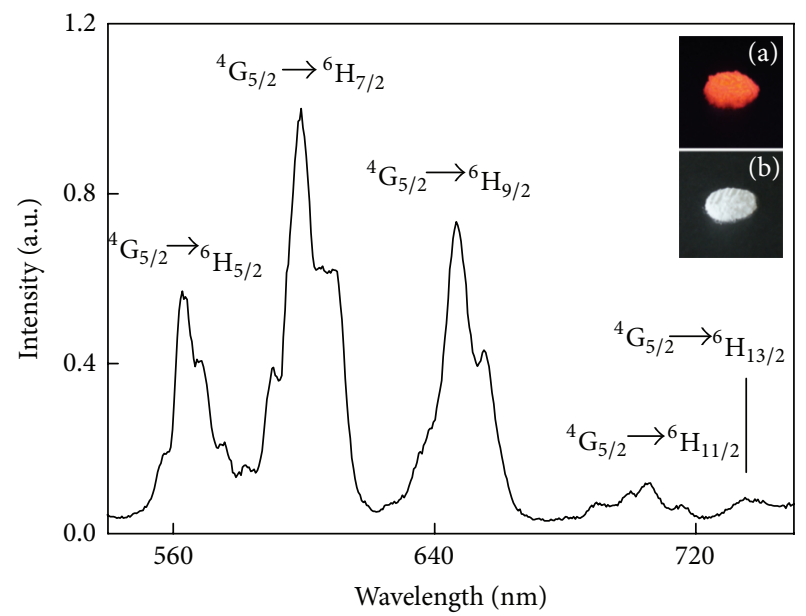

FIGURE 3: Emission spectrum of SLCB phosphor $\left(\lambda_{\mathrm{ex}}=398.0 \mathrm{~nm}\right)$. Inset of (a): fluorescence from SLCB phosphor under $365.0 \mathrm{~nm}$ radiation. Inset of (b): SLCB phosphor under natural light.

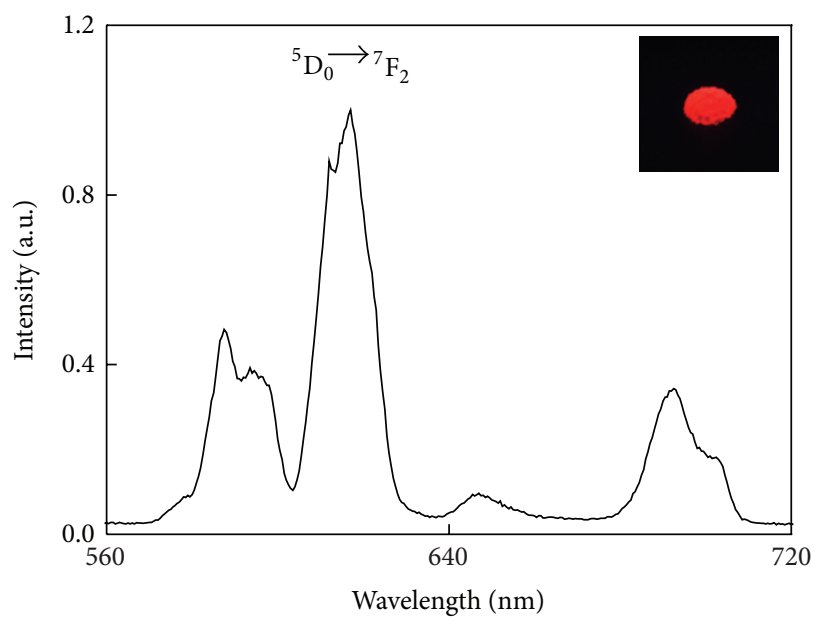

FIgURE 4: Emission spectrum of ELCB phosphor $\left(\lambda_{\mathrm{ex}}=391.0 \mathrm{~nm}\right)$. Inserted photo: fluorescence from ELCB phosphor under $365.0 \mathrm{~nm}$ excitation. 


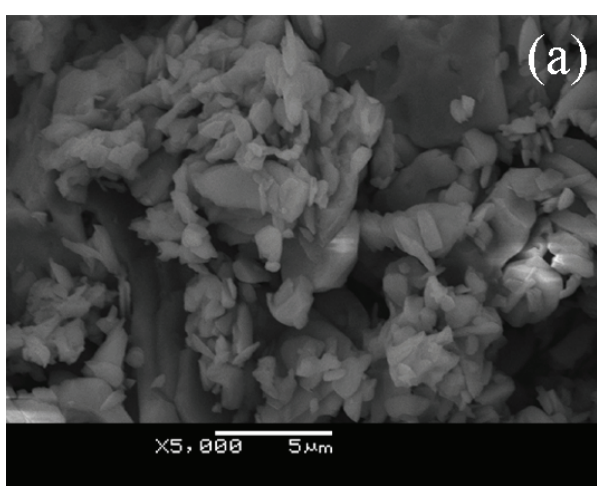

(a)

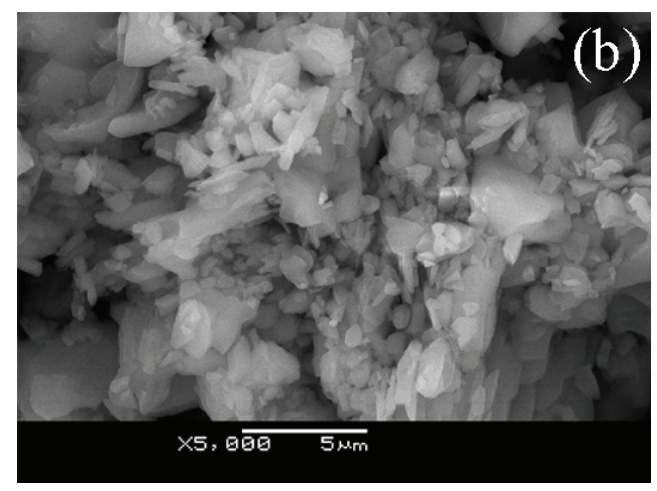

(b)

Figure 5: SEM images of as-prepared SLCB (a) and ELCB (b).

centers in a host lattice on account of its unsplit ${ }^{7} \mathrm{~F}_{0}$ ground state and relatively simple energy level scheme. The symmetry of the crystal site in which $\mathrm{Eu}^{3+}$ is located can be determined by the intensity ratio between ${ }^{5} \mathrm{D}_{0} \rightarrow{ }^{7} \mathrm{~F}_{2}$ and ${ }^{5} \mathrm{D}_{0} \rightarrow$ ${ }^{7} \mathrm{~F}_{1}$ transition emissions in ELCB [64-67]. Here, the ratio is 1.9076 in ELCB phosphor from Figure 4, indicating that ${ }^{5} \mathrm{D}_{0} \rightarrow{ }^{7} \mathrm{~F}_{2}$ electric dipole transition is dominated and $\mathrm{Eu}^{3+}$ is in an inversion asymmetrical site.

Moreover, in order to further identify the asymmetry of $\mathrm{Eu}^{3+}$ in ELCB phosphor, the intensity parameters are calculated. Generally, $J-O$ intensity parameters are derived from absorption spectra; however, in consideration of the special energy level structure of $\mathrm{Eu}^{3+}$, they should be calculated from the emission spectra because the recorded absorption peaks are not enough to get accurate results [68-70]. The transitions of $\mathrm{Eu}^{3+}$ from ${ }^{5} \mathrm{D}_{0}$ to ${ }^{7} \mathrm{~F}_{J}(J=2,4$, and 6) are electronic dipole allowed ones and hypersensitive to the local environment around $\mathrm{Eu}^{3+}$. The spontaneous emission probability $A_{\mathrm{ed}}$ from $|\psi J\rangle$ to $\left|\psi^{\prime} J^{\prime}\right\rangle$ is given by the following expression:

$$
\begin{aligned}
A_{\mathrm{ed}}= & \frac{64 \pi^{4} e^{2} v^{3}}{3 h(2 J+1)} \frac{n\left(n^{2}+2\right)^{2}}{9} \\
& \times \sum_{t=2,4,6} \Omega_{t}\left\langle\psi J\left\|U^{(t)}\right\| \psi^{\prime} J^{\prime}\right\rangle^{2},
\end{aligned}
$$

where $e$ is the electron charge, $v$ is the emission peak wavenumber, $h$ is the Planck constant, $n$ is the refractive index, $2 J+1$ is the degeneracy of the excited state, and $\left\langle\psi J\left\|U^{(t)}\right\| \psi^{\prime} J^{\prime}\right\rangle^{2}$ is the square of the reduced matrix elements of the tensor operator, which connects the initial state $|\psi J\rangle$ with the final state $\left|\psi^{\prime} J^{\prime}\right\rangle$ and is considered to be independent of host matrix. The ${ }^{5} \mathrm{D}_{0} \rightarrow{ }^{7} \mathrm{~F}_{1}$ transition of $\mathrm{Eu}^{3+}$ is magnetic-dipole allowed one and insensitive to the host matrix. The spontaneous emission probability of it $\left(A_{\mathrm{md}}\right)$ is given by

$$
A_{\mathrm{md}}=\frac{64 \pi^{4} v^{3}}{3 h(2 J+1)} n^{3} S_{\mathrm{md}},
$$

where the magnetic dipole line strength $S_{\mathrm{md}}$ is constant and independent of the matrix, so the value of $A_{\text {md }}$ can be estimated by the value of fluoride glass $\left(A_{\mathrm{md}}^{\prime}=60.3 \mathrm{~s}^{-1}\right)$. The relationship is

$$
A_{\mathrm{md}}=\left(\frac{n}{n^{\prime}}\right)^{3} A_{\mathrm{md}}^{\prime}
$$

where $n(=1.679)$ and $n^{\prime}(=1.522)$ are the refractive indices of ELCB crystal [71] and fluoride glass [72], respectively.

Based on the calculated $A_{\text {rad }}$, the selection rules, and the characteristic of transition intensities of $\mathrm{Eu}^{3+}$, each of the $\left\langle\psi J\left\|U^{(t)}\right\| \psi^{\prime} J^{\prime}\right\rangle^{2}$ parameters decides the intensities of transitions because the remaining two are zero. Thus, the $\Omega_{t}$ can be estimated from the intensity ratios of ${ }^{5} \mathrm{D}_{0} \rightarrow{ }^{7} \mathrm{~F}_{2,4}$ transitions to ${ }^{5} \mathrm{D}_{0} \rightarrow{ }^{7} \mathrm{~F}_{1}$ transition as

$$
\begin{aligned}
\frac{\int I(v) d v}{\int I_{\mathrm{md}}(v) d v} & =\frac{A_{J}}{A_{\mathrm{md}}} \\
& =\frac{64 \pi^{4} e^{2} v^{3}}{3 h(2 J+1)} \frac{n\left(n^{2}+2\right)^{2}}{9 A_{\mathrm{md}}} \Omega_{t}\left\langle\psi J\left\|U^{(t)}\right\| \psi^{\prime} J^{\prime}\right\rangle^{2} .
\end{aligned}
$$

The calculated $\Omega_{t}(t=2$ and 4$)$ values of $\mathrm{Eu}^{3+}$ in ELCB phosphor are $3.62 \times 10^{-20}$ and $1.97 \times 10^{-20} \mathrm{~cm}^{2}$, respectively. This result confirms a high inversion asymmetric and strong covalent environment of $\mathrm{Eu}^{3+}$ in the phosphor. The value of $\Omega_{6}$ cannot be given since the ${ }^{5} \mathrm{D}_{0} \rightarrow{ }^{7} \mathrm{~F}_{6}$ emission is unable to be experimentally detected in this work.

Figure 5 presents the SEM pictures of the as-prepared SLCB and ELCB phosphors. The two samples have similar morphology and particle size distribution. Also, they have good dispersion and relatively narrow size distribution with the average size of about $0.5 \sim 6 \mu \mathrm{m}$. However, the particles have no regular and uniform shape, and some of them are agglomerated. The main reasons are that the primary nanocrystals with high energy would assemble to minimize the surface energy and they would be sintered in the heat treatment process. 


\section{Conclusion}

A red emitting phosphor SLCB $\left(\mathrm{Sm}_{x} \mathrm{La}_{2-x} \mathrm{CaB}_{10} \mathrm{O}_{19}\right)$ was prepared by solid-state reaction method in the air. XRD analysis indicates that the crystal belongs to a monoclinic system with unit cell parameters $a=1.1028 \mathrm{~nm}, b=$ $0.6556 \mathrm{~nm}, c=0.9114 \mathrm{~nm}$, and $\beta=91.431^{\circ}$. The excitation spectrum shows that the phosphor can be efficiently excited by the commercial near-UV and blue light emitting diodes. Under the excitation of $398.0 \mathrm{~nm}$, the phosphor presented red luminescence with efficient emissions at 562.0, 598.0, 646.5, 706.0 , and $735.0 \mathrm{~nm}$, corresponding to ${ }^{4} \mathrm{G}_{5 / 2} \rightarrow{ }^{6} \mathrm{H}_{J}(J=$ $5 / 2,7 / 2,9 / 2,11 / 2$, and $13 / 2$ ) transitions, respectively. $\mathrm{Eu}^{3+}$ is used as a spectroscopic probe for the microstructure of ELCB $\left(\mathrm{Eu}_{x} \mathrm{La}_{2-x} \mathrm{CaB}_{10} \mathrm{O}_{19}\right)$ phosphor and, thus, Judd-Ofelt parameters $\Omega_{t}(t=2,4)$ of $\mathrm{Eu}^{3+}$ in ELCB phosphor are derived to be $3.62 \times 10^{-20}$ and $1.97 \times 10^{-20} \mathrm{~cm}^{2}$, indicating a high asymmetrical and covalent environment around rare earth luminescence centers in the host lattice. The red fluorescence suggests that the two phosphors are potential candidates for light emitting diode applications.

\section{Conflict of Interests}

The authors declare that there is no conflict of interests regarding the publication of this paper.

\section{Acknowledgments}

This work was supported by the National Natural Science Foundation of China (Grant no. 61275057) and the Undergraduate Training Programs for Innovation and Entrepreneurship of Dalian Polytechnic University (Grant no. 2013013).

\section{References}

[1] F. Yang, Z. P. Yang, Q. M. Yu, Y. F. Liu, X. Li, and F. C. Lu, "Sm ${ }^{3+}$ doped $\mathrm{Ba}_{3} \mathrm{Bi}\left(\mathrm{PO}_{4}\right)_{3}$ orange reddish emitting phosphor," Spectrochimica Acta A: Molecular and Biomolecular Spectroscopy, vol. 105, pp. 626-631, 2013.

[2] D. Kang, H. S. Yoo, S. H. Jung, H. Kim, and D. Y. Jeon, "Synthesis and photoluminescence properties of a novel redemitting $\mathrm{Na}_{2} \mathrm{Y}_{2} \mathrm{Ti}_{3} \mathrm{O}_{10}: \mathrm{Eu}^{3+}, \mathrm{Sm}^{3+}$ phosphor for white-lightemitting diodes," Journal of Physical Chemistry C, vol. 115, no. 49, pp. 24334-24340, 2011.

[3] Y. H. Won, H. S. Jang, K. W. Cho, Y. S. Song, D. Y. Jeon, and H. K. Kwon, "Effect of phosphor geometry on the luminous efficiency of high-power white light-emitting diodes with excellent color rendering property," Optics Letters, vol. 34, no. 1, pp. 1-3, 2009.

[4] Z. Cui, R. Ye, D. Deng et al., " $\mathrm{Eu}^{2+} / \mathrm{Sm}^{3+}$ ions co-doped white light luminescence $\mathrm{SrSiO}_{3}$ glass-ceramics phosphor for White LED," Journal of Alloys and Compounds, vol. 509, no. 8, pp. 35533558, 2011.

[5] Y. H. Song, G. Jia, M. Yang, Y. J. Huang, H. P. You, and H. J. Zhang, " $\mathrm{Sr}_{3} \mathrm{Al}_{2} \mathrm{O}_{5} \mathrm{Cl}_{2}: \mathrm{Ce}^{3+}, \mathrm{Eu}^{2+}$ : a potential tunable yellow-towhite-emitting phosphor for ultraviolet light emitting diodes," Applied Physics Letters, vol. 49, Article ID 091902, 2009.

[6] H. Yamamoto, "White LED phosphors: the next step," in Optical Components and Materials VII, Proceedings of SPIE, 2010.
[7] M. K. Jung, W. J. Park, and D. H. Yoon, "Photoluminescence characteristics of red phosphor $\mathrm{Eu}^{3+}, \mathrm{Sm}^{3+}$ co-doped $\mathrm{Y}_{2} \mathrm{O}_{3}$ for white light emitting diodes," Sensors and Actuators B: Chemical, vol. 126, no. 1, pp. 328-331, 2007.

[8] S. Nakamura, M. Senoh, N. Iwasa, and S. Nagahama, "Highpower InGaN single-quantum-well-structure blue and violet light-emitting diodes," Applied Physics Letters, vol. 67, p. 1868, 1995.

[9] H. J. Qian, J. Y. Zhang, and L. Q. Yin, "Crystal structure and optical properties of white light-emitting $\mathrm{Y}_{2} \mathrm{WO}_{6}: \mathrm{Sm}^{3+}$ phosphor with excellent color rendering," RSC Advances, vol. 3, no. 23, pp. 9029-9034, 2013.

[10] M. M. Haque, H. I. Lee, and D. K. Kim, "Luminescent properties of Eu3+-activated molybdate-based novel red-emitting phosphors for LEDs," Journal of Alloys and Compounds, vol. 481, pp. 792-796, 2009.

[11] I. Pekgozlu, S. Cakar, and J. Lumin, "Photoluminescence properties of $\mathrm{Li}_{6} \mathrm{CaB}_{3} \mathrm{O}_{8.5}: \mathrm{M}^{3+}\left(\mathrm{M}^{3+}:\right.$ Dy and $\left.\mathrm{Sm}\right)$," Journal of Luminescence, vol. 132, no. 9, pp. 2312-2317, 2012.

[12] H. Yu, D. Deng, D. Zhou et al., " $\mathrm{Ba}_{2} \mathrm{Ca}\left(\mathrm{PO}_{4}\right)_{2}: \mathrm{Eu}^{2+}$ emissiontunable phosphor for solid-state lighting: luminescent properties and application as white light emitting diodes," Journal of Materials Chemistry C, vol. 1, no. 35, pp. 5577-5582, 2013.

[13] S. Neeraj, N. Kijima, and A. K. Cheetham, "Novel red phosphors for solid-state lighting: the system $\mathrm{NaM}\left(\mathrm{WO}_{4}\right)_{2-x}\left(\mathrm{MoO}_{4}\right)_{x}: \mathrm{Eu}^{3+}(\mathrm{M}, \mathrm{Gd}, \mathrm{Y}, \mathrm{Bi}), "$ Chemical Physics Letters, vol. 387, pp. 2-6, 2004.

[14] G. R. Dillip, S. J. Dhoble, L. Manoj, C. Madhukar Reddy, and B. Deva Prasad Raju, "A potential red emitting $\mathrm{K}_{4} \mathrm{Ca}\left(\mathrm{PO}_{4}\right)_{2}$ : $\mathrm{Eu}^{3+}$ phosphor for white light emitting diodes," Journal of Luminescence, vol. 132, no. 11, pp. 3072-3076, 2012.

[15] C. B. Azevedo, É. A. De Souza, E. H. De Faria et al., "Optical properties of Eu-doped hybrid materials prepared from dimethyl and methyl alkoxides precursors," Journal of Luminescence, vol. 134, pp. 551-557, 2013.

[16] Y. G. Su, L. P. Li, and G. S. Li, "Synthesis and optimum luminescence of $\mathrm{CaWO}_{4}$-based red phosphors with codoping of $\mathrm{Eu}^{3+}$ and $\mathrm{Na}^{+}, "$ Chemistry of Materials, vol. 20, no. 19, pp. 60606067,2008

[17] R. J. Wiglusz, T. Grzyb, A. Lukowiak, A. Bednarkiewicz, S. Lis, and W. Strek, "Tuning luminescence properties of $\mathrm{Eu}^{3+}$ doped $\mathrm{CaAl}_{2} \mathrm{O}_{4}$ nanophosphores with $\mathrm{Na}^{+}$co-doping," Journal of Luminescence, vol. 133, pp. 102-109, 2013.

[18] N. S. Hussain, G. Hungerford, R. El-Mallawany et al., "Absorption and emission analysis of $\mathrm{RE}^{3+}\left(\mathrm{Sm}^{3+}\right.$ and $\left.\mathrm{Dy}^{3+}\right)$ : Lithium boro tellurite glasses," Journal of Nanoscience and Nanotechnology, vol. 9, no. 6, pp. 3672-3677, 2009.

[19] M. D. Que, Z. P. Ci, Y. H. Wang, G. Zhu, Y. R. Shi, and S. Y. Xin, "Synthesis and luminescent properties of $\mathrm{Ca}_{2} \mathrm{La}_{8}\left(\mathrm{GeO}_{4}\right)_{6} \mathrm{O}_{2}: \mathrm{RE}^{3+}\left(\mathrm{RE}^{3+}=\mathrm{Eu}^{3+}, \mathrm{Tb}^{3+}, \mathrm{Dy}^{3+}, \mathrm{Sm}^{3+}, \mathrm{Tm}^{3+}\right)$ phosphors," Journal of Luminescence, vol. 144, pp. 64-68, 2013.

[20] A. Tang, D. F. Zhang, and L. Yang, "Photoluminescence characterization of a novel red-emitting phosphor $\operatorname{In}_{2}\left(\mathrm{MoO}_{4}\right)_{3}: \mathrm{Eu}^{3+}$ for white light emitting diodes," Journal of Luminescence, vol. 132, no. 6, pp. 1489-1492, 2012.

[21] S. A. Naidu, S. Boudin, U. V. Varadaraju, and B. Raveau, " $\mathrm{Eu}^{3+}$ and $\mathrm{Tb}^{3+}$ emission in molybdenophosphate $\mathrm{Na}_{2} \mathrm{Y}\left(\mathrm{MoO}_{4}\right)\left(\mathrm{PO}_{4}\right)$," Journal of the Electrochemical Society, vol. 159, no. 4, pp. J122-J126, 2012.

[22] X. L. Dong, J. H. Zhang, X. Zhang, Z. D. Hao, and S. Z. Lv, "Synthesis and photoluminescence properties of $\mathrm{Eu}^{2+}$ 
doped $\mathrm{Sr}_{9} \mathrm{Sc}\left(\mathrm{PO}_{4}\right)_{7}$ phosphors for white light-emitting diodes," Ceramics International, vol. 40, no. 4, pp. 5421-5423, 2014.

[23] P. Abdul Azeem, M. Kalidasan, R. R. Reddy, and K. Ramagopal, "Spectroscopic investigations on Tb3 doped lead fluoroborate glasses," Optics Communications, vol. 285, no. 18, pp. 3787-3791, 2012.

[24] E. Cavalli, P. Boutinaud, R. Mahiou, M. Bettinelli, and P. Dorenbos, "Luminescence dynamics in $\mathrm{Tb}^{3+}$-doped $\mathrm{CaWO}_{4}$ and $\mathrm{CaMoO}_{4}$ crystals," Inorganic Chemistry, vol. 49, no. 11, pp. 4916-4921, 2010.

[25] A. Boukhris, M. Hidouri, B. Glorieux, and M. Ben Amara, "Correlation between structure and photoluminescence of the europium doped glaserite-type phosphate $\mathrm{Na}_{2} \mathrm{SrMg}\left(\mathrm{PO}_{4}\right)_{2}$," Materials Chemistry and Physics, vol. 137, no. 1, pp. 26-33, 2012.

[26] Y. Zhang, C. H. Lu, L. Y. Sun, Z. Z. Xu, and Y. R. Ni, "Influence of $\mathrm{Sm}_{2} \mathrm{O}_{3}$ on the crystallization and luminescence properties of boroaluminosilicate glasses," Materials Research Bulletin, vol. 44, pp. 179-183, 2009.

[27] M. Sobczyk, P. Starynowicz, R. Lisiecki, and W. RybaRomanowski, "Synthesis, optical spectra and radiative properties of $\mathrm{Sm}_{2} \mathrm{O}_{3}: \mathrm{PbO}: \mathrm{P}_{2} \mathrm{O}_{5}$ glass materials," Optical Materials, vol. 30, no. 10, pp. 1571-1575, 2008.

[28] V. Venkatramu, P. Babu, C. K. Jayasankar, T. Tröster, W. Sievers, and G. Wortmann, "Optical spectroscopy of $\mathrm{Sm}^{3+}$ ions in phosphate and fluorophosphate glasses," Optical Materials, vol. 29, no. 11, pp. 1429-1439, 2007.

[29] S. Nishiura, S. Tanabe, K. Fujioka, and Y. Fujimoto, "Properties of transparent Ce:YAG ceramic phosphors for white LED," Optical Materials, vol. 33, no. 5, pp. 688-691, 2011.

[30] X. M. Zhang and H. J. Seo, "Luminescence properties of novel $\mathrm{Sm}^{3+}, \mathrm{Dy}^{3+}$ doped LaMoBO 6 phosphors," Journal of Alloys and Compounds, vol. 509, pp. 2007-2010, 2011.

[31] A. M. Pires, M. F. Santos, M. R. Davolos, and E. B. Stucchi, “The effect of $\mathrm{Eu}^{3+}$ ion doping concentration in $\mathrm{Gd}_{2} \mathrm{O}_{3}$ fine spherical particles," Journal of Alloys and Compounds, vol. 344, no. 1-2, pp. 276-279, 2002.

[32] K. Driesen, V. K. Tikhomirov, and C. Gorller-Walrand, "Eu ${ }^{3+}$ as a probe for rare-earth dopant site structure in nano-glassceramics," Journal of Applied Physics, vol. 102, Article ID 024312, 2007.

[33] C. H. Yan, L. D. Sun, C. S. Liao et al., " $\mathrm{Eu}^{3+}$ ion as fluorescent probe for detecting the surface effect in nanocrystals," Applied Physics Letters, vol. 82, no. 20, pp. 3511-3513, 2003.

[34] R. Stefani, A. D. Maia, E. E. S. Teotonio, M. A. F. Monteiro, M. C. F. C. Felinto, and H. F. Brito, "Photoluminescent behavior of $\mathrm{SrB}_{4} \mathrm{O}_{7}: \mathrm{RE}^{2+}(\mathrm{RE}=\mathrm{Sm}$ and $\mathrm{Eu})$ prepared by Pechini, combustion and ceramic methods," Journal of Solid State Chemistry, vol. 179, no. 4, pp. 1086-1092, 2006.

[35] Y. Won, H. Jang, W. Im, D. Jeon, and J. Lee, "Red-emitting $\mathrm{LiLa}_{2} \mathrm{O}_{2} \mathrm{BO}_{3}: \mathrm{Sm}^{3+}, \mathrm{Eu}^{3+}$ phosphor for near-ultraviolet lightemitting diodes-based solid-state lighting," Journal of The Electrochemical Society, vol. 155, no. 9, pp. J226-J229, 2008.

[36] M. Ayvacıkl1, A. Ege, and N. Can, "Radioluminescence of $\mathrm{SrAl}_{2} \mathrm{O} 4: \mathrm{Ln}^{3+}$ (Ln = Eu, Sm, Dy) phosphor ceramic," Optical Materials, vol. 34, no. 1, pp. 138-142, 2011.

[37] Y. M. Yang, Z. Y. Ren, Y. C. Tao, Y. M. Cui, and H. Yang, "Eu ${ }^{3+}$ emission in $\mathrm{SrAl}_{2} \mathrm{~B}_{2} \mathrm{O}_{7}$ based phosphors," Current Applied Physics, vol. 9, pp. 618-621, 2009.

[38] D. Tu, Y. J. Liang, R. Liu, Z. Cheng, F. Yang, and W. L. Yang, "Photoluminescent properties of $\mathrm{LiSr}_{x} \mathrm{Ba}_{1-x} \mathrm{PO}_{4}: \mathrm{RE}^{3+}$ $\left(\mathrm{RE}=\mathrm{Sm}^{3+}, \mathrm{Eu}^{3+}\right) \mathrm{f}-\mathrm{f}$ transition phosphors," Journal of Alloys and Compounds, vol. 509, no. 18, pp. 5596-5599, 2011.
[39] J. H. Hao, J. Gao, and M. Cocivera, “Tuning of the blue emission from europium-doped alkaline earth chloroborate thin films activated in air," Applied Physics Letters, vol. 82, no. 17, pp. 2778$2780,2003$.

[40] A. E. Henkes and R. E. Schaak, "Synthesis of nanocrystalline $\mathrm{REBO}_{3}(\mathrm{RE}=\mathrm{Y}, \mathrm{Nd}, \mathrm{Sm}, \mathrm{Eu}, \mathrm{Gd}, \mathrm{Ho})$ and $\mathrm{YBO}_{3}:$ Eu using a borohydride-based solution precursor route," Journal of Solid State Chemistry, vol. 181, no. 12, pp. 3264-3268, 2008.

[41] G. F. Ju, Y. H. Hu, H. Y. Wu et al., "A red-emitting heavy doped phosphor $\mathrm{Li}_{6} \mathrm{Y}\left(\mathrm{BO}_{3}\right)_{3}$ : $\mathrm{Eu}^{3+}$ for white light-emitting diodes," Optical Materials, vol. 33, pp. 1297-1301, 2011.

[42] J. Yang, C. M. Zhang, C. X. Li, Y. G. Yu, and J. Lin, "Energy transfer and tunable luminescence properties of $\mathrm{Eu}^{3+}$ in $\mathrm{TbBO}_{3}$ microspheres via a facile hydrothermal process," Inorganic Chemistry, vol. 47, no. 16, pp. 7262-7270, 2008.

[43] Y. C. Wu, J. G. Liu, P. Z. Fu et al., "A new lanthanum and calcium borate $\mathrm{La}_{2} \mathrm{CaB}_{10} \mathrm{O}_{19}$," Chemistry of Materials, vol. 13, no. 3, pp. 753-755, 2001.

[44] H. Lin, D. Hou, L. Li, Y. Tao, and H. Liang, "Luminescence and site occupancies of $\mathrm{Eu}^{3+}$ in $\mathrm{La}_{2} \mathrm{CaB}_{10} \mathrm{O}_{19}$," Dalton Transactions, vol. 42, no. 36, pp. 12891-12897, 2013.

[45] Y. Chen, J. Wang, C. M. Liu, X. J. Kuang, and Q. Su, "A host sensitized reddish-orange $\mathrm{Gd}_{2} \mathrm{MoO}_{6}: \mathrm{Sm}^{3+}$ phosphor for light emitting diodes," Applied Physics Letters, vol. 98, Article ID 081917, 2011.

[46] V. Kumar, A. K. Bedyal, S. S. Pitale, O. M. Ntwaeaborwa, and H. C. Swart, "Synthesis, spectral and surface investigation of $\mathrm{NaSrBO}_{3}: \mathrm{Sm}^{3+}$ phosphor for full color down conversion in LEDs," Journal of Alloys and Compounds, vol. 554, pp. 214-220, 2013.

[47] Y. Zhou and B. Yan, " $R E_{2}\left(\mathrm{MO}_{4}\right)_{3}: \mathrm{Ln}^{3+}(\mathrm{RE}=\mathrm{Y}, \mathrm{La}, \mathrm{Gd}, \mathrm{Lu} ; \mathrm{M}=$ $\mathrm{W}, \mathrm{Mo} ; \mathrm{Ln}=\mathrm{Eu}, \mathrm{Sm}, \mathrm{Dy})$ microcrystals: controlled synthesis, microstructure and tunable luminescence," CrystEngComm, vol. 15, no. 28, pp. 5694-5702, 2013.

[48] S. A. Yan, J. W. Wang, Y. S. Chang, W. S. Hwang, and Y. H. Chang, "Synthesis and luminescence properties of $\mathrm{Ln}^{3+}\left(\mathrm{Ln}^{3+}\right.$ $=\mathrm{Er}^{3+}, \mathrm{Sm}^{3+}$ )-doped barium lanthanum tungstate $\mathrm{BaLa}_{2} \mathrm{WO}_{7}$ phosphors," Optical Materials, vol. 34, no. 1, pp. 147-151, 2011.

[49] Z. G. Xia and D. M. Chen, "Synthesis and luminescence properties of $\mathrm{BaMoO}_{4}: \mathrm{Sm}^{3+}$ phosphors," Journal of the American Ceramic Society, vol. 93, no. 5, pp. 1397-1401, 2010.

[50] F. He, P. Yang, D. Wang et al., "Hydrothermal synthesis, dimension evolution and luminescence properties of tetragonal $\mathrm{LaVO}_{4}: \mathrm{Ln}\left(\mathrm{Ln}=\mathrm{Eu}^{3+}, \mathrm{Dy}^{3+}, \mathrm{Sm}^{3+}\right)$ nanocrystals," Dalton Transactions, vol. 40, no. 41, pp. 11023-11030, 2011.

[51] G. S. R. Raju, J. Y. Park, H. C. Jung et al., "Excitation induced efficient luminescent properties of nanocrystalline $\mathrm{Tb}^{3+} / \mathrm{Sm}^{3+}: \mathrm{Ca}_{2} \mathrm{Gd}_{8} \mathrm{Si}_{6} \mathrm{O}_{26}$ phosphors," Journal of Materials Chemistry, vol. 21, no. 17, pp. 6136-6139, 2011.

[52] X. Lin, X. S. Qiao, and X. P. Fan, "Synthesis and luminescence properties of a novel red $\mathrm{SrMoO}_{4}: \mathrm{Sm}^{3+}, \mathrm{R}^{+}$phosphor," Solid State Sciences, vol. 13, no. 3, pp. 579-583, 2011.

[53] Z. Yang, Z. Zhao, M. Que, and Y. Wang, "Photoluminescence and thermal stability of $\beta$-SiAlON:Re $(\operatorname{Re}=S m$, Dy) phosphors," Optical Materials, vol. 35, no. 7, pp. 1348-1351, 2013.

[54] M. Puchalska and E. Zych, "The effect of charge compensation by means of $\mathrm{Na}^{+}$ions on the luminescence behavior of $\mathrm{Sm}^{3+}$ doped $\mathrm{CaAl}_{4} \mathrm{O}_{7}$ phosphor," Journal of Luminescence, vol. 132, no. 3, pp. 826-831, 2012.

[55] G. Lakshminarayana, R. Yang, J. R. Qiu, M. G. Brik, G. A. Kumar, and I. V. Kityk, "White light emission from $\mathrm{Sm}^{3+} / \mathrm{Tb}^{3+}$ 
codoped oxyfluoride aluminosilicate glasses under UV light excitation," Journal of Physics D: Applied Physics, vol. 42, no. 1, Article ID 015414, 2009.

[56] P. L. Li, Z. J. Wang, Z. P. Yang, Q. L. Guo, and X. Li, "Emission features of $\mathrm{LiBaBO}_{3}: \mathrm{Sm}^{3+}$ red phosphor for white LED," Materials Letters, vol. 63, no. 9-10, pp. 751-753, 2009.

[57] M. N. Huang, Y. Y. Ma, X. Y. Huang, S. Ye, and Q. Y. Zhang, "The luminescence properties of $\mathrm{Bi}^{3+}$ sensitized $\mathrm{Gd}_{2} \mathrm{MoO}_{6}: \mathrm{RE}^{3+}$ $(\mathrm{RE}=\mathrm{Eu}$ or $\mathrm{Sm})$ phosphors for solar spectral conversion," Spectrochimica Acta A, vol. 115, pp. 767-771, 2013.

[58] S. Tang, M. Huang, J. Wang, F. Yu, G. Shang, and J. $\mathrm{Wu}$, "Hydrothermal synthesis and luminescence properties of GdVO 4: $\operatorname{Ln}^{3+}(\mathrm{Ln}=\mathrm{Eu}, \mathrm{Sm}, \mathrm{Dy})$ phosphors," Journal of Alloys and Compounds, vol. 513, pp. 474-480, 2012.

[59] N. Zhang, C. Guo, and H. Jing, "Photoluminescence and cathode-luminescence of $\mathrm{Eu}^{3+}$-doped $\mathrm{NaLnTiO}_{4}(\mathrm{Ln}=\mathrm{Gd}$ and Y) phosphors," RSC Advances, vol. 3, no. 20, pp. 7495-7502, 2013.

[60] L. Q. An, J. Zhang, M. Liu, S. Chen, and S. W. Wang, "Preparation and photoluminescence of $\mathrm{Sm}^{3+}$ and $\mathrm{Eu}^{3+}$ doped $\mathrm{Lu}_{2} \mathrm{O}_{3}$ phosphor," Optical Materials, vol. 30, no. 6, pp. 957-960, 2008.

[61] S. C. Prashantha, B. N. Lakshminarasappa, and B. M. Nagabhushana, "Photoluminescence and thermoluminescence studies of $\mathrm{Mg}_{2} \mathrm{SiO}_{4}: \mathrm{Eu}^{3+}$ nano phosphor," Journal of Alloys and Compounds, vol. 509, no. 42, pp. 10185-10189, 2011.

[62] L. Chen, G. T. Yang, J. Q. Liu, X. Shu, G. B. Zhang, and Y. Jiang, "Photoluminescence properties of and in host under vacuum ultraviolet/ultraviolet excitation," Journal of Applied Physics, vol. 105, no. 1, Article ID 013513, 2009.

[63] A. Dhahri, K. Horchani-Naifer, A. Benedetti, F. Enrichi, and M. Ferid, "Combustion synthesis and photoluminescence of $\mathrm{Eu}^{3+}$ doped $\mathrm{LaAlO}_{3}$ nanophosphors," Optical Materials, vol. 34, no. 11, pp. 1742-1746, 2012.

[64] S. Mishra, R. Rajeswari, N. Vijayan et al., "Probing the structure, morphology and multifold blue absorption of a new redemitting nanophosphor for LEDs," Journal of Materials Chemistry C, vol. 1, no. 37, pp. 5849-5855, 2013.

[65] W. A. Pisarski, J. Pisarska, G. Dominiak-Dzik, and W. RybaRomanowski, "Transition metal $\left(\mathrm{Cr}^{3+}\right)$ and rare earth $\left(\mathrm{Eu}^{3+}\right.$, $\mathrm{Dy}^{3+}$ ) ions used as a spectroscopic probe in compositionaldependent lead borate glasses," Journal of Alloys and Compounds, vol. 484, no. 1-2, pp. 45-49, 2009.

[66] L. A. Bueno, A. S. Gouveia-Neto, E. B. da Costa, Y. Messaddeq, and S. J. L. Ribeiro, "Structural and spectroscopic study of oxyfluoride glasses and glass-ceramics using europium ion as a structural probe," Journal of Physics Condensed Matter, vol. 20, no. 14, Article ID 145201, 2008.

[67] A. Ellens, F. Zwaschka, F. Kummer, A. Meijerink, M. Raukas, and K. Mishra, "Sm ${ }^{2+}$ in BAM: fluorescent probe for the number of luminescing sites of $\mathrm{Eu}^{2+}$ in BAM," Journal of Luminescence, vol. 93, no. 2, pp. 147-153, 2001.

[68] J. Huang, J. Loriers, and P. Porcher, "Spectroscopic properties of some $\mathrm{Eu}^{3+}$ doped scheelite-related rare earth sesquimolybdates and sesquitungstates," Journal of Solid State Chemistry, vol. 48, no. 3, pp. 333-345, 1983.

[69] M. Karbowiak, A. Mech, A. Bednarkiewicz, and W. Stręk, "Synthesis and properties of solution-processed $\mathrm{Eu}^{3+}: \mathrm{BaY}_{2} \mathrm{~F}_{8}$ ", Journal of Luminescence, vol. 114, no. 1, pp. 1-8, 2005.

[70] Y. Tian, B. J. Chen, R. N. Hua et al., "Optical transition, electron-phonon coupling and fluorescent quenching of
$\mathrm{La}_{2}\left(\mathrm{MoO}_{4}\right)_{3}: \mathrm{Eu}^{3+}$ phosphor," Journal of Applied Physics, vol. 109, Article ID 053511, 2011.

[71] M. Dejneka, E. Snitzer, and R. E. Riman, "Blue, green and red fluorescence and energy transfer of $\mathrm{Eu}^{3+}$ in fluoride glasses," Journal of Luminescence, vol. 65, no. 5, pp. 227-245, 1995.

[72] R. Guo, Y. C. Wu, P. Z. Fu, and F. L. Jing, "Optical transition probabilities of $\mathrm{Er}^{3+}$ ions in $\mathrm{La}_{2} \mathrm{CaB}_{10} \mathrm{O}_{19}$ crystal," Chemical Physics Letters, vol. 416, no. 1-3, pp. 133-136, 2005. 

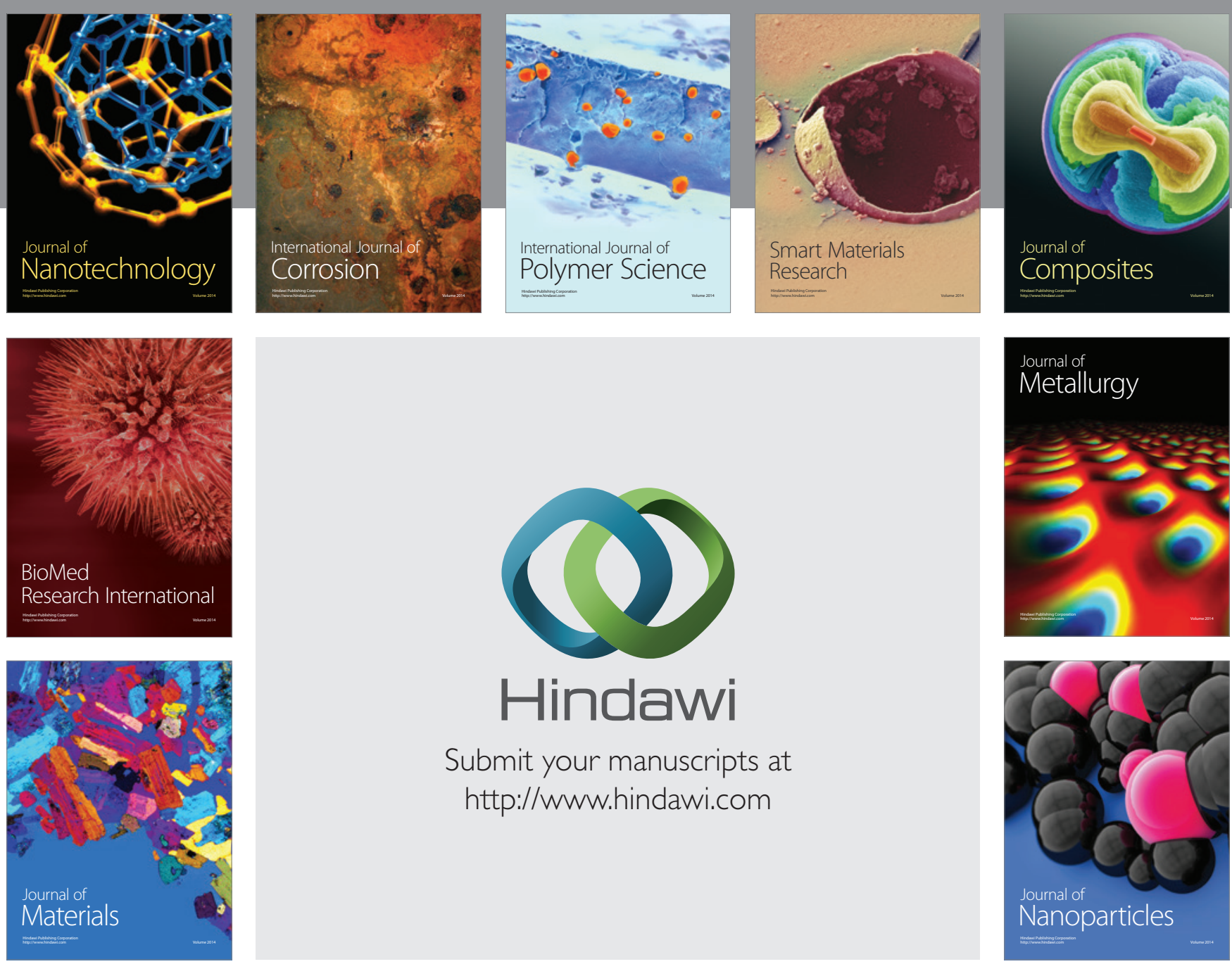

Submit your manuscripts at http://www.hindawi.com
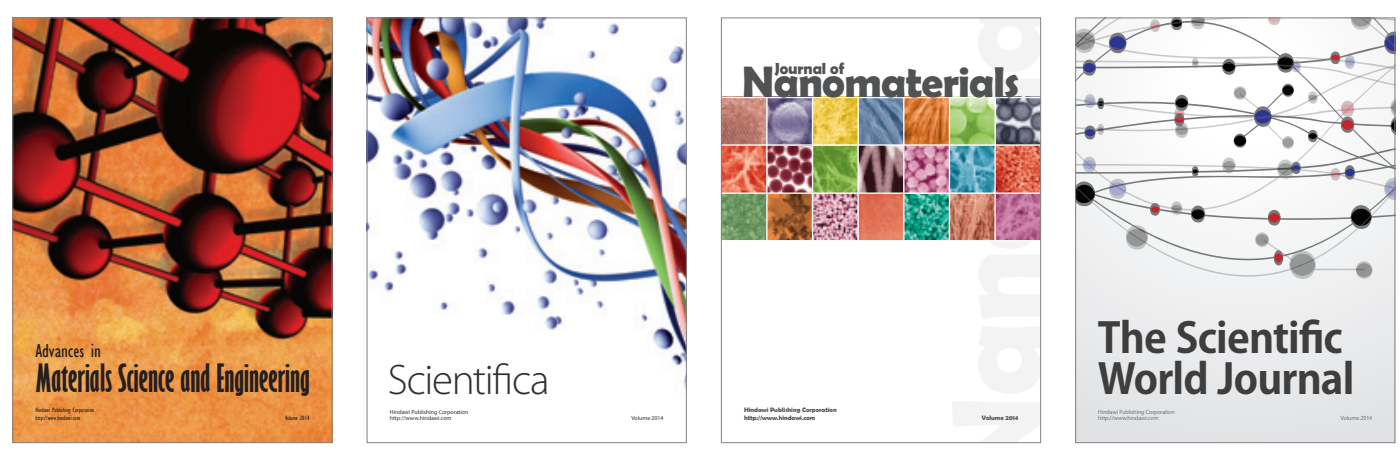

\section{The Scientific World Journal}
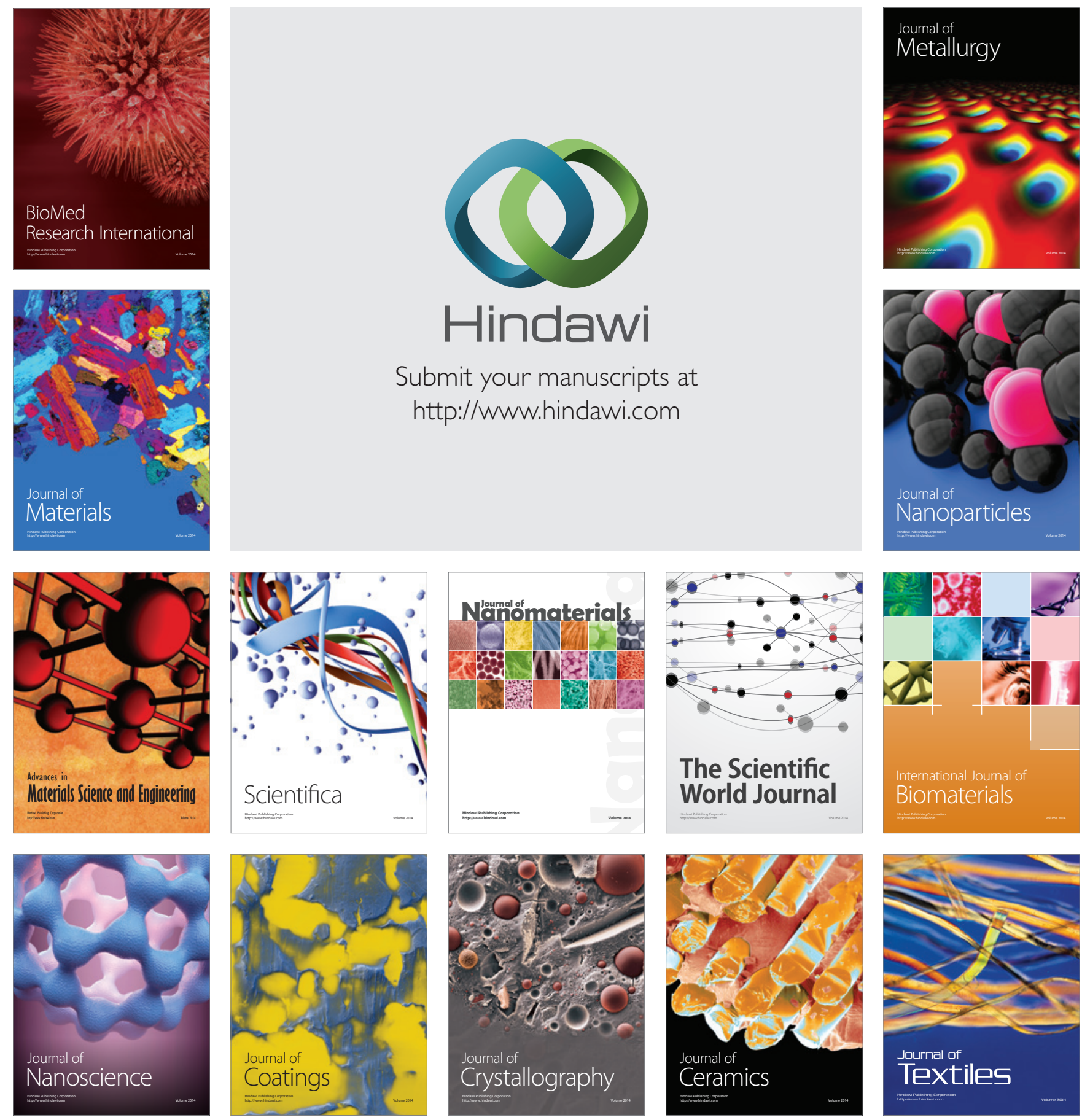